— ORIGINAL ARTICLE Volume 9 Issue 32017

DOI: 10.21315/eimj2017.9.3.3

ARTICLE INFO

Submitted: $16-05-2017$

Accepted: 29-07-2017

Online: 30-09-2017

\section{Sleep Quality among Pre-Clinical Medical Students in Universiti Putra Malaysia and Universiti Malaya, Malaysia}

\author{
Sie Tien Ngu', Krishnaraja Masalamany², Nizar Abd Manan ${ }^{3}$, Siti \\ Khadijah Adam ${ }^{3}$
}

${ }^{1} M D$ Programme, Faculty of Medicine and Health Sciences, ${ }^{2}$ Bachelor of Mechanical Engineering Programme, Faculty of Engineering,

${ }^{3}$ Pharmacology Unit, Department of Human Anatomy, Faculty of Medicine and Health Sciences, Universiti Putra Malaysia, MALAYSIA

To cite this article: Ngu ST, Masalamany K, Abd Manan N, Adam SK. Sleep quality among pre-clinical medical students in Universiti Putra Malaysia and Universiti Malaya, Malaysia. Education in Medicine Journal. 2017;9(3): 23-31. https://doi.org/10.21315/eimj2017.9.3.3

To link to this article: https://doi.org/10.21315/eimj2017.9.3.3

\title{
ABSTRACT
}

Introduction: Poor sleep quality among university students has become an important issue to be concerned as it can hugely influence the students especially on their academic performance. However, there are inadequate studies published on the sleep quality of medical students in Malaysia. Objective: This study aimed at determining the sleep quality of pre-clinical medical students in Universiti Putra Malaysia (UPM) and Universiti Malaya (UM). Methods: This is a cross-sectional study that used self-administered questionnaire to collect data from the pre-clinical medical students of UPM and UM. Sleep quality of the students was measured using Pittsburgh Sleep Quality Index (PSQI) questionnaire. All data were analysed by SPSS version 21. Results: Findings revealed that $63.9 \%$ respondents with poor sleep quality (PSQI score: more than 5). The prevalence of poor sleepers in UM (67\%) was slightly higher compared to UPM (60.9\%). However, the comparison of PSQI score showed no significant difference between UPM and UM respondents $(p=0.082)$. Meanwhile, the average sleep duration per night among respondents was 5 hours 39 minutes ( $\pm 1.21 \mathrm{hrs}$ ), whereas only $6.1 \%$ students practiced recommended sleep value per night ( $>7 \mathrm{hrs}$ ). Significant association was found between caffeine intake and sleep quality. Besides, this present study showed no association between sleep quality with gender and year of study. Conclusion: Majority of the pre-clinical students in UPM and UM had poor sleep quality and short sleep duration. Only a small number of students practiced recommended sleep value per night.

Keywords: Sleep quality, Pittsburgh Sleep Quality Index (PSQI), Medical students

CORRESPONDING AUTHOR Siti Khadijah Adam, PhD, Pharmacology Unit, Department of Human Anatomy, Faculty of Medicine and Health Sciences, Universiti Putra Malaysia, 43400 UPM Serdang, Selangor, Malaysia | Email: sk.adam@upm.edu.my 


\section{INTRODUCTION}

Sleep enhances memory consolidation in human (1) that thus improves learning processes (2). Sleep plays a crucial role in memory consolidation in which memories are reorganised, made more resistant to interference and may result in an improvement of performance (3). For instance, academic performance of students is closely related to their sleep quality (4).

Buysse et al. described sleep quality as quantitative aspects of sleep such as sleep duration, sleep latency or number of arousals, and subjective subjects such as depth or restfulness of sleep (5). Compared to other academic programmes, students taking medicine are probably at a higher risk of having poor sleep quality due to their packed schedule and heavy load of study (6). This might also be caused by high level of stress, work pressures and night time activities commonly encountered by medical students. Previous study has reported that medical students experienced more disturbed sleep patterns compared to nonmedical students (7). Furthermore, another study conducted in a university in Saudi Arabia reported a high prevalence of poor sleep quality among medical students (8).

Sleep quality in students may be influenced by several factors such as gender, year of study (9-11), caffeine intake, smoking and alcohol consumption, which have been proven to be the factors of poor sleep quality (12-13). Those with poor sleep quality have been reported to experience more academic stress. Meanwhile, decreased academic performance in medical students was due to their poor sleep habits such as decreased nocturnal sleep time, late bedtime during weekdays and weekends, catch-up sleep on weekends and increased daytime sleepiness (14).

Pittsburgh Sleep Quality Index (PSQI) developed by Buysse et al. is a validated questionnaire used to estimate sleep quality and disturbances over a month (5). It is a suitable tool to identify a variety of sleep disturbances and sleep problems. In fact, PSQI possesses good psychometric properties and is consistent with previous studies (13).

Therefore, the present study was conducted to determine the level of sleep quality among pre-clinical students in Universiti Putra Malaysia (UPM) and Universiti Malaya (UM) using PSQI. This study will be able to identify the quality of sleep experienced by the students and its association with their socio-demographic profile and daily lifestyle.

\section{Methods}

\section{Study Design and Population}

The study was conducted at Faculty of Medicine and Health Sciences, UPM and Faculty of Medicine, UM. The selected study population was all pre-clinical medical students (Year 1 and Year 2) of both universities. A cross-sectional study design was utilised to get the required information from April to August 2014.

The sample size estimated using two sample proportions was 234 . The prevalence value for the calculation was adopted from that proposed by Araújo et al. (9) and the associating factor used was gender. The population was selected using stratified sampling method, which was divided into two strata namely UPM and UM. Then, proportionate allocation was done so that the sample size of each stratum will be proportionate to the population size of the stratum when viewed against the entire population. Lastly, simple random sampling method was applied within each stratum.

The data was collected using a selfadministered questionnaire that is divided into two sections; first section includes the socio-demographic profile such as gender, race, year of study, weight, height and university, whereas the second section is the PSQI questionnaire that measures the sleep quality and sleep disturbances of the students over a month (5). 
Prior the commencement of the study, ethical clearance was obtained from Ethic Committee for Research Involving Human Subjects of UPM (FPSK (EXP14-medic) U033). Approval letter to carry out the study in UPM and UM as well as the consent form from respondents were also obtained.

\section{Statistical Analysis}

Statistical Package for Social Sciences Programme (SPSS) Version 21 was used to analyse the data. Descriptive analysis was used to determine the frequency and percentage. Pearson's Chi-square test was used to test the association between dependent and independent variables. Mann-Whitney test was utilised to examine the significant differences between two continuous variables for data not equally distributed. All levels of significance were set at a standard $p$ value of 0.05 .

\section{Results}

A total of 234 questionnaires were given out. From that, only 180 questionnaires were returned back. Data of all 180 respondents were recorded, indicating the response rate of $76.9 \%$.

The socio-demographic profiles of respondent are described in Table 1. Among 180 respondents, 92 respondents $(51.1 \%)$ were from UPM while another 88 respondents (48.9\%) were from UM. About $32.8 \%$ of the respondents were male and $67.2 \%$ were female. There was a predominance of Malay respondents $(53.3 \%)$ observed. Nevertheless, this study focused on pre-clinical students, which were first year students $(55 \%)$ and second year students $(45 \%)$.

\section{PSQI Score and Sleep Quality}

The overall global PSQI score was $6.27 \pm 2.50$. The mean global PSQI score for UPM and UM respondents was $5.95 \pm 2.54$ and 6.61 \pm 2.43 , respectively (Table 2). There was no significant difference of PSQI score between UPM and UM students $(z=-1.737, p=0.082)$. Mean value was computed for each seven subscales of PSQI. Among the seven subscales of PSQI score, component 3, which is sleep duration, obtained the highest mean of more than 2 for both universities. Subscales with mean more than 1 were recognised as areas most contributing to PSQI score.

Table 3 shows a high prevalence of poor sleep quality $(63.9 \%)$ among the 180 respondents. It is apparent that there are $60.9 \%(\mathrm{n}=56)$ of UPM students and $67.0 \%(n=59)$ of UM students with poor sleep quality. Subsequently, there was no association between sleep quality with gender $\left(x^{2}=0.581, p=0.446\right)$ and year of study $\left(x^{2}=1.368, p=0.242\right)$.

Nonetheless, there was an association between caffeine intake and sleep quality $\left(x^{2}\right.$ $=10.529, p=0.015$ ).

\section{Sleep Patterns}

Based on Table $4,88.9 \%$ of the respondents often go to bed after midnight. The mean bed time of the respondents was 12.41 am $( \pm 1.02 \mathrm{hrs})$, while the mean rise time was $6.38 \mathrm{am}( \pm 1.10 \mathrm{hrs})$. The mean sleep duration per night was 5 hours and 39 minutes $( \pm 1.21 \mathrm{hrs})$. Only $6.1 \%$ of the respondents had more than seven hours sleep duration. Majority respondents $(45.6 \%)$ had less than five hours sleep per night.

\section{Factors Affecting Sleep Quality Rated by Students}

Table 5 describes five factors affecting sleep quality. The students were asked to rank the factors by $1-5$ where 1 is the most relevant factors affecting sleep quality while 5 is the least relevant factors affecting their sleep quality. From the result, majority students had chosen 'early classes on weekdays', 'long lecture hours throughout the day' and 'assessment stress' as the most relevant factors affecting their sleep quality. On the other hand, 'Assignments' and 'cocurriculum activities' were ranked as less relevant factors. 
Table 1: Socio-demographic profile of the study respondents $(n=180)$

\begin{tabular}{lcccc}
\hline & & UPM & UM & Overall \\
Gender & n (\%) & $\mathbf{n}(\%)$ & $\mathbf{n}(\%)$ \\
& Male & $34(51.1)$ & $25(28.4)$ & $59(32.8)$ \\
Ethnicity & $58(48.9)$ & $63(71.6)$ & $121(67.2)$ \\
& Female & $92(100.0)$ & $88(100.0)$ & $180(100.0)$ \\
& Total & $51(55.4)$ & $45(51.1)$ & $96(53.3)$ \\
& Malay & $28(30.4)$ & $19(21.6)$ & $47(26.1)$ \\
Year & $13(14.1)$ & $20(22.7)$ & $33(18.3)$ \\
& Chinese & 0 & $4(4.5)$ & $4(2.3)$ \\
& Indian & $92(100.0)$ & $88(100.0)$ & $180(100.0)$ \\
& Others & $43(46.7)$ & $56(63.6)$ & $99(55.0)$ \\
& Total & $49(53.3)$ & $32(36.4)$ & $81(45.0)$ \\
\hline
\end{tabular}

Table 2: Mean global PSQI score and its seven subscales for all respondents

\begin{tabular}{lccc}
\hline & UPM & UM & Overall \\
& Mean \pm SD & Mean \pm SD & Mean \pm SD \\
Global PSQI score & $5.95 \pm 2.54$ & $6.61 \pm 2.43$ & $6.27 \pm 2.50$ \\
Subjective sleep quality & $0.97 \pm 0.78$ & $1.22 \pm 0.82$ & $1.09 \pm 0.81$ \\
Sleep latency & $0.87 \pm 0.76$ & $1.10 \pm 0.79$ & $0.98 \pm 0.78$ \\
Sleep duration & $2.03 \pm 1.00$ & $2.30 \pm 0.82$ & $2.16 \pm 0.92$ \\
Habitual sleep efficiency & $0.22 \pm 0.53$ & $0.10 \pm 0.31$ & $0.16 \pm 0.44$ \\
Sleep disturbances & $1.01 \pm 0.46$ & $1.02 \pm 0.37$ & $1.02 \pm 0.42$ \\
Use of sleep medication & $0.07 \pm 0.25$ & $0.05 \pm 0.21$ & $0.06 \pm 0.23$ \\
Daytime dysfunction & $0.78 \pm 0.68$ & $0.83 \pm 0.78$ & $0.81 \pm 0.73$ \\
\hline
\end{tabular}

Table 3: Sleep quality among respondents

\begin{tabular}{lcccc}
\hline & & UPM & UM & Overall \\
Sleep quality & $\mathbf{n}(\%)$ & $\mathbf{n}(\%)$ & $\mathbf{n}(\%)$ \\
& Normal & $36(39.1)$ & $29(33.0)$ & $65(36.1)$ \\
& Poor & $56(60.9)$ & $59(67.0)$ & $115(63.9)$ \\
& Total & $92(100.0)$ & $88(100.0)$ & $180(100.0)$ \\
\hline
\end{tabular}


Table 4: Sleep patterns of respondents

\begin{tabular}{|c|c|c|c|c|}
\hline & & Frequency & Percent & Mean \pm SD \\
\hline \multirow[t]{6}{*}{ Bed time } & $11.00-11.59$ pm & 20 & 11.1 & $12.41 \pm 1.02 \mathrm{am}$ \\
\hline & $12.00-12.59 \mathrm{am}$ & 79 & 43.9 & \\
\hline & $1.00-1.59 \mathrm{am}$ & 43 & 23.9 & \\
\hline & $2.00-2.59 \mathrm{am}$ & 30 & 16.7 & \\
\hline & $3.00-4.00 \mathrm{am}$ & 8 & 4.4 & \\
\hline & Total & 180 & 100.0 & \\
\hline \multirow[t]{9}{*}{ Rise time } & $3.00-3.59 \mathrm{am}$ & 1 & 6 & $6.38 \pm 1.10 \mathrm{am}$ \\
\hline & $4.00-4.59 \mathrm{am}$ & 1 & 6 & \\
\hline & $5.00-5.59 \mathrm{am}$ & 29 & 16.1 & \\
\hline & $6.00-6.59 \mathrm{am}$ & 74 & 41.1 & \\
\hline & $7.00-7.59 \mathrm{am}$ & 54 & 30.0 & \\
\hline & $8.00-8.59 \mathrm{am}$ & 10 & 5.6 & \\
\hline & $9.00-9.59 \mathrm{am}$ & 7 & 3.9 & \\
\hline & $>10.00 \mathrm{am}$ & 4 & 2.2 & \\
\hline & Total & 180 & 100.0 & \\
\hline \multirow[t]{5}{*}{ Sleep duration } & $>7$ hours & 11 & 6.1 & $5.39 \pm 1.21$ hours \\
\hline & 6-7 hours & 31 & 17.2 & \\
\hline & $5-6$ hours & 56 & 31.1 & \\
\hline & $<5$ hours & 82 & 45.6 & \\
\hline & Total & 180 & 100.0 & \\
\hline
\end{tabular}

Table 5: The mode of score for factors affecting sleep quality $(1=$ most relevant factor, $5=$ least relevant factor)

\begin{tabular}{lc}
\hline \multicolumn{1}{c}{ Factors } & Mode \\
Early classes on weekdays & 1 \\
Long lecture hours throughout the day & 1 \\
Assessment stress & 1 \\
Assignments & 4 \\
Co-curriculum activities & 5 \\
\hline
\end{tabular}




\section{DISCUSSION}

PSQI score above 5 was indicated as poor sleep quality (5). It was observed that UPM and UM students had poor sleep quality based on the mean PSQI score. At the same time, majority of them $(76.1 \%)$ rated their own sleep quality as good. This shows that majority students are not aware that they are actually having poor sleep quality. The mean PSQI score from this study was quite close to that from Brick et al. where the score was $6.37 \pm 2: 57$ (10). In their study, $50.9 \%$ of the students were found to be poor sleepers.

The comparison conducted between UPM and UM has suggested that the prevalence of poor sleepers in UM is slightly higher than UPM. This slight difference in prevalence was because UM students were having their final exam study week during the period of data collections while UPM students had just completed their final exams. However, no significant difference in PSQI score was found between UPM and UM. Thus, the difference in academic schedule in both universities does not generally affect their sleep quality.

From this study, the prevalence of poor sleep quality was slightly higher in male compared to female. However, Chi-square test showed no significant association between gender and sleep quality. This finding is similar to a study by Cardoso et al. in Brazil, which demonstrated no statistically significant association between sleep quality and gender (6). Similarly, previous study by Lai and Say (15) also showed no significant difference between male and female with poor sleep quality. In addition, prevalence of poor sleep quality is higher among 1st year students compared to 2 nd year students with insignificant relationship between year of study with sleep quality. A study carried out on medical students from a university in the United States reported that there was a relationship between class year and sleep quality (10). Earlier class years have been reported to have worse sleep quality than later class years. It is possible that later- year students may have developed better coping strategies for their study and time management.

Majority respondents of this study did not take caffeine or energy booster drinks, while $13 \%$ of them had coffee every day. Chi-square test showed that there was a significant relationship between sleep quality and caffeine intake. For example, previous study has been done to determine the use of energy drinks and other caffeinated beverages among college students in Peru (16). The results proved that poor sleep quality was associated with consumption of caffeinated beverages. Besides, $67.3 \%$ of the medical students in India were seen to regularly consume caffeinated beverages and more likely to experience sleep disturbances, leading to a poor sleep quality (17). Previous study by Drake et al. had proved that it is better to avoid or reduce caffeine intake before sleep as caffeine could remain in body average of 3 to 5 hours causing the body to have difficulty to rest (18). The study also recommended people to avoid consuming caffeine at least six hours before sleep to ensure a good quality of sleep.

In this present study, sleep duration was observed as the major component in PSQI contributing to high PSQI score. The mean sleep duration of the respondents was 5 hours 39 minutes per night. Additionally, majority respondents $(45.6 \%)$ had less than 5 hours of sleep per night. Only $6.1 \%$ of the respondents had more than seven hours of sleep duration per night. It is recommended for adults to have seven to nine hours sleep per night for optimum recovery (19). Pilcher and Huffcutt defined sleep deprivation as functioning with less than five hours of sleep from the previous night (20). Thus, we could conclude that majority respondents in this present study were sleep deprived. A study conducted in International Medical University (IMU) Malaysia presented medical students with relatively higher sleep duration than our respondents where $51.2 \%$ of them had sleep duration of more than seven hours (21). This could be due to the time that this present study was conducted 
when UM students are having their study week. They spent more time studying at night and are more anxious about their examination. Another reason may be due to long lecture hours in UPM and UM during daytime, which restricted their daytime activities and indirectly increased their night time activities that lead to a shorter sleep duration.

This study has listed five factors affecting the sleep quality (early classes in weekdays, long lecture hours throughout the day, assessment stress, assignments, and cocurriculum activities). The students were asked to rank the factors by 1 to 5 with 1 as the most relevant factors affecting sleep quality while 5 is the least relevant factors affecting their sleep quality. From the result, majority of them have selected early classes, long lecture hours and assessment stress as the most relevant factors affecting their sleep quality. In previous study by Britz and Pappas, university students ranked academic workload as the most stressful component affecting them (22). It was also found that academic workload had significant association with sleep patterns. Lund et al. showed a high correlation between academic stress and sleep quality (23). Moreover, those with poor sleep quality were reported to have experienced more academic stress. Students may need to have a good time management skill and familiarise themselves with a hectic schedule to prepare them in their working life as a doctor. On the other hand, majority of them ranked co-curriculum activity as the least relevant factor. Even though some students complained that co-curriculum activities sometimes consume much time, their involvement in the extra co-curriculum activities may take their mind off from their academic stress and allow them to develop their soft skills such as teamwork, leadership and time management.

A previous study assessing the sleepwake pattern of medical students has been conducted (24), which showed that time of class initiation in the morning affected the students' sleep-wake pattern and directly influenced their sleep quality. Besides, sleep deprivation was partly due to class schedules. Analysis of the PSQI in the study showed a statistically significant improvement in sleep quality of the students with a later schedule. About $42.3 \%$ of the students had poor sleep quality when they had early schedule. Subsequently, the prevalence decreased to $11.5 \%$ students when they had later schedule. Furthermore, the evening class students had longer sleep duration and better sleep quality compared to morning class students. Therefore, it can be concluded that the respondents in the present study had poor sleep quality due to schedule since their classes usually begin at $8 \mathrm{am}$ and ends in the evening daily.

A lot of studies consistently showed that medical students who sleep well at night with a good quality of sleep do better academically (4, 14, 25). Students with more sleeping hours on an average night tend to obtain slightly better grades (26). Thus, it is very important for students regardless of their programme to have a good quality of sleep to achieve better academic performance.

\section{CONCLUSION}

Majority of the pre-clinical medical students in UPM and UM had poor sleep quality. The prevalence of poor sleepers in UM was slightly higher than UPM. However, there was no significant difference between PSQI score among respondents from both universities. The average sleep duration per night among these students were also inadequate. Only a small number of students practiced recommended sleep value per night. Future studies should be performed to gather information on the causes or effects of poor sleep quality among medical students. It is also recommended for the students to be exposed to the importance of having a good sleep quality and better time management. Better sleeping habit practices can improve their sleep quality and eventually their academic performance. 


\section{ACKNOWLEDGEMENTS}

The authors are grateful to Universiti Putra Malaysia and University of Malaya for giving us the approval to conduct this study. They also thank all the respondents who are willing to participate in the study.

\section{REFERENCES}

1. Diekelmann S. Sleep for cognitive enhancement. Front Sys Neurosci. 2014;8:46. https://doi.org/10.3389/ fnsys.2014.00046

2. Eliasson AH, Lettieri CJ, Eliasson AH. Early to bed, early to rise! Sleep habits and academic performance in college students. Sleep Breath. 2010;14(1):71-5. https://doi. org/10.1007/s11325-009-0282-2.

3. Lewis PA, Durrant SJ. Overlapping memory replay during sleep builds cognitive schemata. Trends Cogn Sci. 2011;15(8):343-51. https://doi. org/10.1016/j.tics.2011.06.004.

4. Lemma S, Berhane Y, Worku A, Gelaye B, Williams M. Good quality sleep is associated with better academic performance among university students in Ethiopia. Sleep Breath. 2013;18(2):1-7. https://doi.org/10.1007/ s11325-013-0874-8.

5. Buysse DJ, Reynolds III CF, Monk TH, Berman SR, Kupfer DJ. The Pittsburgh Sleep Quality Index: a new instrument for psychiatric practice and research. Psychiatry Res. 1989;28(2):193-213. https://doi. org/10.1016/0165-1781(89)90047-4.

6. Cardoso HC, Bueno F, Mata JCD, Alves APR, Jochims I, VazFilho IHR, Hanna MM. Assessing quality of sleep in medical students. Revista Brasileira de Educação Médica. 2009;33(3):349-55. https://doi. org/10.1590/S0100-55022009000300005.

7. Anjum A, Bajwa M, Saeed R. Sleep patterns; among medical and non-medical students of university of Lahore, 2010-11. Professional Medical Journal. 2014;21(1):148-56.
8. Mahfouz MS, Ageely H, Al-Saruri SM, Aref LA, Heje NH, Al-attas, SA, Abdulhaq AM, Arishy MA, Al-omar AA, Maqbol SA, Madkhali TY, Bani IA. Sleep quality among students of the Faculty of Medicine in Jazan University, Saudi Arabia. MiddleEast Journal of Scientific Research, 2013;16(4):508-13.

9. Araújo M, Lima A, Araújo $T$, Veras V, Zanetti M, Damasceno M. Association of sociodemografic factors and sleep quality in Brazilian university students. Texto \& Contexto-Enfermagem. 2014;23(1):17684. https://doi.org/10.1590/S010407072014000100021.

10. Brick C, Seely D, Palermo T. Association between sleep hygiene and sleep quality in medical students. Behav Sleep Med. 2010;8(2):113-21. https://doi. org/10.1080/15402001003622925.

11. van Zundert RM, van Roekel E, Engels RC, Scholte RH. Reciprocal associations between adolescents' night-time sleep and daytime affect and the role of gender and depressive symptoms. JYouth Adolesc. 2015;44(2):55669. https://doi.org/10.1007/s10964-0130009-3.

12. Lohsoonthorn V, Khidir H, Casillas G, Lertmaharit S, Tadesse MG, Pensuksan WC, Rattananupong T, Gelaye B, Williams MA. Sleep quality and sleep patterns in relation to consumption of energy drinks, caffeinated beverages, and other stimulants among Thai college students. Sleep Breath. 2013;17(3):1017-28. https://doi. org/10.1007/s11325-012-0792-1.

13. Zunhammer M, Eichhammer P, Busch V. Sleep quality during exam stress: the role of alcohol, caffeine and nicotine. PLoS ONE. 2014;9(10):e109490. https://doi. org/10.1371/journal.pone.0109490. 
14. BaHammam A, Alaseem A, Alzakri A, Almeneessier A, Sharif $M$. The relationship between sleep and wake habits and academic performance in medical students: a cross-sectional study. BMC Med Educ. 2012;12(1):61. https://doi. org/10.1186/1472-6920-12-61.

15. Lai PP, Say YH. Associated factors of sleep quality and behavior among students of two tertiary institutions in Northern Malaysia. Med J Malaysia. 2013;68(3):195-203.

16. Sanchez SE, Martinez C, Oriol RA, Yanez D, Castañeda B, Sanchez E, Gelaye B, Williams MA. Sleep quality, sleep patterns and consumption of energy drinks and other caffeinated beverages among Peruvian college students. Health (Irvine Calif). 2013;5(8B):26-35. https://doi.org/10.4236/ health.2013.58A2005.

17. Giri P, Baviskar M, Phalke D. Study of sleep habits and sleep problems among medical students of Pravara Institute of Medical Sciences Loni, Western Maharashtra, India. Ann Med Health Sci Res. 2013;3(1):51-4. https://doi.org/10.4103/2141-9248.109488.

18. Drake C, Roehrs T, Shambroom J, Roth T. Caffeine effects on sleep taken 0, 3, or 6 hours before going to bed. J Clin Sleep Med. 2013;9(11):1195-200. https://doi. org/10.5664/jcsm.3170.

19. Hirshkowitz M, Whiton K, Albert SM, Alessi C, Bruni O, DonCarlos L, Hazen N, Herman J, Katz ES, Kheirandish-Gozal L, Neubauer DN, O'Donnell AE, Ohayon M, Peever J, Rawding R, Sachdeva RC, Setters B, Vitiello MV, Ware JC, Hillard PJA. National Sleep Foundation's sleep time duration recommendations: methodology and results summary. Sleep Health. 2015;1(1):40-3. https://doi.org/10.1016/j. sleh.2014.12.010.
20. Pilcher JJ, Huffcutt AI. Effects of sleep deprivation on performance: a meta-analysis. Sleep. 1996;19(4):318-26. https://doi. org/10.1093/sleep/19.4.318.

21. Zailinawati AH, Teng CL, Chung YC, Teow TL, Lee PN, Jagmohni KS. Daytime sleepiness and sleep quality among Malaysian medical students. Med J Malaysia. 2009;64(2):108-10.

22. Britz J, Pappas E. Sources and outlets of stress among university students: correlations between stress and unhealthy habits. URJHS. 2010;9(1).

23. Lund HG, Reider BD, Whiting AB, Prichard JR. Sleep patterns and predictors of disturbed sleep in a large population of college students. J Adolesc Health. 2010;46(2):124-32. https://doi. org/10.1016/j.jadohealth.2009.06.016.

24. Medeiros ALD, Araujo JF. Sleep-wake pattern of medical students: early versus late class starting time. Braz J Med Biol Res. 2002;35:1373-77. https://doi.org/10.1590/ S0100-879X2002001100016.

25. Azad MC, Fraser K, Rumana N, Abdullah AF, Shahana N, Hanly PJ, Turin TC. Sleep disturbances among medical students: a global perspective. J Clin Sleep Med 2015;11(1):69-74. https://doi.org/10.5664/ jcsm. 4370 .

26. Zeek ML, Savoie MJ, Song M, Kennemur LM, Qian J, Jungnickel PW, Westrick SC. Sleep duration and academic performance among student Pharmacists. Am J Pharm Educ. 2015;79(5):63. https://doi. org/10.5688/ajpe79563. 